\title{
The Role of Different Social Reinforcement Contingencies in Inducing Echoic Tacts through Motor Imitation Responding in Children with Severe Language Delays
}

\author{
Ioanna Tsiouri \& R. D. Greer
}

\begin{abstract}
The study investigated the role of social reinforcement, when teaching two preschoolers with no functional vocal verbal behavior first instances of echoic responses, using rapid motor imitation responding. The dependent variables for the experiment were: (1) echoic tacts (echoics presented under the controlling variables of tacts) and (2) generalized motor imitation responses to the rapid motor imitation antecedent procedure (Ross \& Greer, 2003; Tsiouri \& Greer, 2003). Three single case reversal experimental designs were implemented, counterbalanced across two conditions: (1) delivery of praise and social reinforcement contingently upon only correct rapid motor imitation and echoic responses and (2) delivery of generalized social interaction on a fixed time schedule without extinction of correct echoic responses. Results showed that the number of echoics significantly increased during the contingent social reinforcement condition, when compared with the fixed time delivery condition, during which data consistently remained at a lower level, while motor imitation responding remained at high levels during both experimental conditions. These findings are discussed in terms of: a) whether motor imitation and vocal verbal imitation comprise two different response classes controlled by different setting events, yet may be joined as higher order operant by the procedure used and b) the importance of social reinforcement, when teaching first instances of echoic tacts, through rapid motor imitation responding. Keywords: Language delays, motor imitation, echoics, tacts, social reinforcement, noncontingent delivery of preferred item.
\end{abstract}

One of the major challenges that special educators are presented with when working with children with developmental disabilities is teaching vocal communication skills to nonvocal children. About $50 \%$ of children with autism do not display functional speech and they require intensive behavioral interventions to acquire an effective communication system (Whetherby \& Prizant, 2000; Williams \& Greer, 1993).

Skinner in his book Verbal Behavior (1957) identified several verbal functions distinguished by the occasions in which they occur and the consequences they produce. The three verbal operants directly or indirectly related to this study are the echoic, the mand and the tact. Echoic verbal behavior is defined as the verbal response under the control of verbal stimuli that generates a sound pattern similar to that of the stimulus (Skinner, 1957). For example, after an adult says "cat", a child responds, "cat." The critical characteristic of echoic verbal behavior is the point-to-point correspondence between the verbal stimulus and the response, as well as the temporal relation between the stimulus and the response (later reproduction of overheard speech is not echoic behavior). Another critical characteristic is that the reinforcer for the tact is a generalized reinforcer that is typically social in nature (Greer \& Ross, 2008).

The mand is a verbal operant that specifies its reinforcer, under the functional control of relevant conditions of deprivation or aversive stimulation. For example, the response "I want water" is 
evoked under conditions of deprivation from water and specifies to the listener that water will be an effective reinforcer. The tact is controlled by a nonverbal discriminative stimulus (an object, event or property of an object or event) and is reinforced by a non-specific generalized conditioned reinforcement, such as attention, praise or repetition of the response (Stafford, Sundberg \& Braam, 1988). For example, a child says, "airplane" in the presence of an actual airplane. A listener consequates this response saying, "that's right, it is an airplane."

Skinner's (1957) theory of verbal behavior gave rise to empirical research that investigated the verbal operants he identified and led to the development of applied instructional tactics and curricula. Whetherby and Prizant (2000) described a shift from highly structured "discrete trial" training curricula (Lovaas, 1977) to contemporary applied behavioral analysis approaches, which incorporate the environmental variables that control verbal behavior on a moment-to-moment basis (i.e., deprivation, satiation, aversive stimulation conditions, generalized social reinforcement, stimulus control, history of the organism, natural context in which communication occurs) (Greer \& Ross, 2008; Hall \& Sundberg, 1987; Hart \& Risely, 1974; Partington \& Sundberg, 1998). However, one need not wait for naturally occurring conditions to evoke verbal operants, since recent work has shown that the motivating conditions can be designed, thus ensuring many more opportunities to acquire the verbal operants (Fiorile \& Greer, 2007; Greer \& Ross, 2008; Pistoljevic \& Greer, 2006; Schauffler \& Greer, 2006)

Williams and Greer (1993) introduced the echoic to mand and the echoic to tact teaching operations for verbal behavior, where the student has to emit a certain number of echoic responses before being presented with opportunities for independent responses, mands or tacts. During the echoic to mand procedure, the therapist creates momentary deprivation states from preferred items, through a choice component (two preferred items are introduced at the same time). During the echoic to tact procedure, correct tacting of non-preferred items results in a generalized reinforcer (e.g., token or praise) and/or the opportunity to mand a preferred item.

Establishing operations or "motivative" variables, such as deprivation, satiation or aversive stimulation play a critical role in the acquisition of mands (Michael, 1982; Michael, 1983; Michael, 2000; Skinner, 1957). Deprivation often refers to restricted access to preferred items, while satiation or abolishing operations are considered equivalent with unrestricted access to preferred items. Michael (2000) gave an interesting example of how to produce a decrease in the reinforcing effectiveness of a preferred item through satiation. He suggested that attention given noncontingently by caregivers to infants (touching, eye contact, verbal praise) might function as an abolishing operation or satiation, while restricted access might function as an establishing or motivational operation for responses such as crying or other infant vocalization.

In accordance with Michael's (2000) example, the noncontingent reinforcement (NCR) control procedure defined as the delivery of a reinforcer according to a schedule that is not response contingent or response dependent (Cooper, Heron and Heward, 1986; Thompson \& Iwata, 2005), was utilized in order to investigate the role of contingent social reinforcement in inducing generalized motor and vocal imitation in infants (Bijou and Baer, 1967; Poulson and Kymissis, 1988; Poulson and Kymisses, 1996). They demonstrated that delivery of contingent parental interaction (smiles, taps, tickles) resulted in an increase of infant vocalization and of imitative responses (both motor and vocal), during training and generalized probe trials, when compared to a baseline condition, during which 
social interaction was delivered non-contingently as a form of free interaction between the infant and the caregiver.

Two explanations have been proposed for the observed response suppression during the NCR procedure: a) satiation to the reinforcer being delivered (Marcus \& Vollmer, 1996) and b) extinction, being defined as elimination of the reinforcement contingency following the target response (Hagopian, Crocket, Van Stone, Deleon, Bowman, 2000; Lalli, Casey, and Kates, 1997). There have been several clinical studies that investigated the role of the two mechanisms in the effectiveness of NCR in reducing the target response (Car, Bailey, Ecott, Lucker, Weil, 1998; Fisher, Iwata, Mazzaleski, 1997; Goh, Iwata, Deleon, 2000; Kahng, Iwata Deleon and Wallace, 2000; Lalli, Casey, and Kates, 1997). In most studies the NCR procedure has been implemented with an implicit extinction component. That is, the target behavior's reinforcer was delivered only on a time-based schedule and never contingently upon the target behavior. However, Lalli and colleagues (1997) tested the effects of a NCR without extinction procedure (delivery of a preferred item both contingently and non contingently with regard to the target behavior) and found that this procedure was effective in suppressing behavior although the original reinforcement contingency of the target behavior remained in place. Fisher, Iwata, Mazzaleski, (1997) demonstrated that even when arbitrary stimuli are delivered noncontingently, while reinforcers of the target behavior are delivered contingently upon it, still there is suppression of the target behavior. These studies provided evidence against the extinction hypothesis as a mechanism of response suppression during the NCR procedure. Goh, et al., (2000) alternatively suggested the need to discriminate between thick and thin NCR schedules. They demonstrated that during thick NCR schedules, response suppression results from satiation, while during thin NCR schedules; response suppression is a result of extinction.

The NCR procedure was reconsidered and refined by Poling and Normand (1999) and Vollmer (1999), who suggested that using the term "reinforcement" for the description of the response independent delivery of stimuli is not appropriate, since there is nothing in this procedure that bears the operational characteristic of reinforcement (measured increase in the rate of a response). Therefore, fixed time (FT) stimulus delivery would be a more precise term than noncontingent reinforcement or better yet fixed time (FT) delivery of preferred items.

Baer, Peterson, and Sherman, (1967); Poulson (1983); Reynolds, (1961) compared levels of infant vocalization under an experimental condition in which social stimulation was delivered contingent on vocalization according to an FR 1 schedule with those observed under a DRO control condition in which social stimulation was presented every $2 \mathrm{~s}$ in the absence of vocalization. Despite the higher densities of reinforcer delivery under the DRO schedule, the typically developing infants engaged in higher levels of responding under experimental (FR 1) conditions, suggesting that vocalization was sensitive to the social reinforcement delivered contingent on the response. In summary, both the NCR procedure, with its parametric variations (with or without extinction, with or without schedule thinning), and the DRO procedure seem to have interesting applications in the acquisition of verbal behavior and in strengthening first instances of vocal verbal behavior in infants.

Another thematic line of research in the acquisition of verbal behavior investigated the role of imitation (motor, vocal or object use imitation) as a predictor of language acquis ition and retention (Gaines, Leaper, Monahan, \& Wickgenant, 1988; Partington \& Sundberg, 1998; Poulson \& Kymissis, 1996; Yoder \& Layton, 1988). Several research studies have investigated whether motor imitation generalized to vocal imitation when only motor imitation receives training. They found that there are 
distinct topographical boundaries between imitative response classes (Garcia, Baer \& Firestone, 1971; Young, Krantz, McClannahan \& Poulson, 1994). In contrast to these findings, Sherman (1965) extended the class of motor imitation to include vocal responses, by fading in modeled responses that were closer approximations to vocalizations, such as mouth opening, blowing, emitting unvoiced sounds and finally voiced sounds. Peterson (1968) and Steinman \& Boyce (1971) were successful in inducing non-imitative responses (one-step directions) that were never trained before, when these were interspersed among reinforced imitative responses.

Ross \& Greer (2003); Tsiouri and Greer (2003) were successful in inducing first instances of echoic and independent mands and tacts in children with no functional vocal (echoic or independent) communication. They combined the rapid performance of large and small motor imitations with the echoic to mand teaching operations for verbal behavior (Williams \& Greer, 1993; Greer, \& Keohane, 2005; Greer \& Ross, 2008). The Rapid Motor Imitation Antecedent (RMIA) procedure consisted of a sequence of six motor responses modeled by the instructor with the antecedent "do this". The instructor rapidly and randomly modeled six (three gross motor and six small motor) actions, which the participants imitated one by one, as they were presented. Large motor actions were defined as large muscle movements such as clap hands, touch head, tap knees, tap table, stomp feet, raise hand. The small motor actions were behaviors modeled on the instructor's face (touch nose, touch eye, touch teeth, open mouth).

The RMIA was combined with the echoic to mand and echoic to tact teaching operations for verbal behavior (Williams \& Greer, 1993). According to this procedure the participant is required to emit a set number of echoic responses before instruction shifts to spontaneous functional verbal behavior, under the respective controlling variables of the mand or the tact. In Tsiouri and Greer (2003) the participant had to emit 2 consecutive correct echoics (mands or tacts) with the RMIA procedure and 8 consecutively correct echoics (mands or tacts) without the RMIA, before instruction switched to independent mand or tact responding. The RMIA procedure was successful in inducing echoic and independent mands and tacts. One interesting finding was that tacts (echoic and independent) required fewer opportunities than mands for mastery to criterion (Tsiouri and Greer, 2003). This finding contradicts previous research literature that suggests that mands are acquired faster than tacts and should be taught first (Caroll \& Hesse, 1987; Stafford, et al., 1988; Sundberg, Milani, Partington, 1977). Moreover, research with typically developing children suggests that the tact response is predominant (Hart \& Risely, 1995, 1999). Faster acquisition of echoic and independent tacts was attributed to the variability and quality of reinforcers available, during echoic and independent tact instruction, as well as the opportunity to choose a reinforcer as a consequence for correct responses. However, further research is needed to investigate the role of generalized social reinforcement as a controlling variable in the acquisition of echoic and independent tacts, when the RMIA procedure is in effect.

The purpose of the study reported here was to investigate the role that different contingencies of social reinforcement play in the effectiveness of the RMIA procedure to induce first instances of echoic tacts (echoics taught under the controlling variables of tacts) (Tsiouri \& Greer, 2003). Thus, two experimental conditions were implemented: one of Fixed Time delivery of generalized social interaction without extinction (related to possible satiation effects) (Car, et al., 1998; Fisher, et al.,1997; Goh, et al., 2000; Kahng, et al., 2000; Lalli, et al., 1997), and one of contingent only upon correct motor imitation and echoic tact responses delivery of generalized social reinforcement. We posed two experimental questions: 1) Would different contingencies of delivery of social 
reinforcement control the effectiveness of the RMIA procedure in inducing echoic tacts? 2) Would those different social reinforcement contingenc ies affect the RMIA responding?

Method

\section{Participants}

Participant A was a 5-year-old male, diagnosed with Pervasive Developmental Disorder, who according to the Preschool Inventory of Repertoires for Kindergarten (PIRK) (Greer \& McCorkle, 1996), followed one-step and two-step directions, and demonstrated a generalized motor imitation repertoire (large and small motor actions). He could make eye contact with a person or an item for two seconds and could sit still in his chair for ten seconds upon request. He could echo, though not consistently, some vocalizations (ga, ah, ba), contingent upon the teacher's antecedent (a mean of two correct out of twenty responses).

Participant B was a 4-year and 2 months old female, diagnosed with Pervasive Developmental Disorder. Based on the PIRK assessment (Greer \& McCorkle, 1996), had no functional vocal verbal behavior, but textually responded independently to 20 letters of the alphabet. However, there was no echoic vocal verbal behavior in her repertoire. She could functionally use signs to mand-preferred items (5 signs). In terms of listener skills, she could follow one-step directions and she could also perform generalized motor imitation actions (both large and small motor actions), without receiving any prior explicit training. She could also make eye contact with the instructor for 2 seconds upon request and sit still in the chair for 8 seconds.

Both participants were chosen for this study because they satisfied four main criteria: they were under good instructional control (could sit still for 10 and 8 seconds respectively and attend to instructional material upon teacher's request) and they had generalized motor imitation in their repertoire. They both lacked functional communication skills, and they had very limited echoic behavior. Based on both participants' anecdotal instructional history, many forms of social interaction, such as the teacher's vocal praise, hugs, kisses, tickles and smiles functioned as educational reinforcement (Skinner, 1957).

\section{Setting}

The study was conducted in a special education school for preschoolers (2-5 years old) with disabilities. The school followed the Comprehensive Application of Behavior Analysis to Schooling $\left(\mathrm{CABAS}^{\circledR}\right)$ model (Greer. 2001; Greer \& Keohane, 2004; Greer, Keohane \& Healy, 2002; Greer, McCorkle, \& Willliams, 1989; Selinske, Greer, \& Lodhi, 1991). The study was conducted in a fullday self-contained classroom (6 students, one teacher, two teacher assistants), where data collection was part of the daily instructional routine. The data collection lasted approximately two months. Definition of Behaviors

Dependent Variables. Data were collected on: 1) the number of correct echoic tacts for the vocal verbal forms "cup" and "book" for participant A and "paper" for participant B. Correct responses had point to point correspondence with a vocal model, emitted in the presence of the corresponding non-verbal stimulus, and they were consequated by contingent generalized social reinforcement (Skinner, 1957; Tsiouri and Greer, 2003; Williams and Greer, 1993). The instructor 
presented an actual cup, book or paper (non-verbal stimulus and at the same time he emitted the vocal model for the forms "cup", "book" and "paper" respectively. The forms were chosen after it was determined, through a preference assessment test (choice assessment) (Piazza, Fischer, Hagopian, Bowman, Lisa, 1996), that cups, books, and papers were not preferred items for participants A and B respectively. This assessment was necessary in order to exclude any reinforcing or motivational effects that these items might have had on each participant's echoic responding, which in this case would create confounding in terms of the role of generalized social reinforcement as the only reinforcer in effect.

2) Data were also collected on the rapid motor imitation antecedent (RMIA) (Ross \& Greer, 2003; Tsiouri \& Greer, 2003). It consisted of a sequence of six motor responses modeled by the instructor with the antecedent "do this". The instructor rapidly and randomly modeled six (three large motor and three small motor) actions, which the participants imitated one by one, as they were presented. Large motor actions were defined as large muscle movements such as clap hands, touch head, tap knees, tap table, stomp feet, raise hand. The small motor actions were behaviors modeled on the instructor's face (touch nose, touch eye, touch teeth, open mouth). The last motor action presented was always a small motor action around the mouth area (touch mouth, open mouth or show teeth). The RMIA always preceded the instructor's vocal model for "cup", "book" and "paper."

Contingent Generalized Social Reinforcement Delivery and Fixed Time (FT) Delivery of Social Interaction without Extinction. The independent variables of the study were two different contingencies of reinforcement: a) delivery of generalized social reinforcement contingent upon only correct motor and echoic tact responses, and b) FT delivery of generalized social interaction without extinction, that is FT delivery of generalized social interaction upon incorrect motor or echoic tacts, combined with contingent upon correct motor and echoic tact responses delivery of generalized social reinforcement, (related to a possible satiation condition) (Fisher, et al.,1997;Goh, et al., 2000; Guerin, 1994; Kahng, et al., 2000; Lalli, et al., 1997; Vollmer and Hackenberg, 2001). Generalized social interaction was operationally defined as making eye contact, praising, smiling, hugging, kissing or tickling the participant.

\section{Data Collection}

Data were collected on both the RMIA responses and the echoic tact responses. A data form and a pencil were used to record the participants' responses in blocks of 20 trial sessions. Each time the participants emitted six correct motor actions (RMIA) one plus (+) was recorded. If the participants emitted at least one incorrect motor imitation response, then a minus (-) was recorded for the whole RMIA sequence. Therefore, RMIA data were not response specific, but response class specific, since the participants had a generalized motor imitation repertoire. A second column on the data form was used to record correct (+) or incorrect (-) echoic tact responses.

\section{Interobserver Agreement}

Interobserver Agreement (IOA) was calculated on the number of correct RMIA responses and on the number of correct echoics emitted by the two participants, across baseline, and the two experimental conditions. IOA was calculated for each session by dividing the total number of point to point agreements by the total number of agreements plus disagreements and multiplying by $100 \%$. Interobserver agreement data were collected during 30\%-35\% of sessions per each condition. The 
mean IOA for Participant's A RMIA responses was 100\%, and for the number of correct echoic tacts was $96 \%$ (range, $88 \%-100 \%$ ). For Participant B the mean IOA was 98\% (range, 90\%-100\%) for RMIA responses and 97\% (range, 94\%-100\%) for echoic tacts.

\section{Design}

Two reversal experimental designs (ABAB), counterbalanced across two different reinforcement contingencies of reinforcement were implemented, in order to teach participant A two echoic tacts ("cup" and "book"). More specifically, the two conditions that were counterbalanced were: a) contingent on correct motor and echoic tact responses delivery of generalized social reinforcement and b) Fixed Time (FT) delivery of social interaction contingent upon incorrect responses, without extinction of correct responses (contingent delivery of social reinforcement upon correct responses). The two conditions had to be counterbalanced across two echoic tact forms in order to control for possible sequence effects. Participant B was introduced in the study to systematically replicate the second reversal design on Participant B, by teaching another echoic tact form ("paper").

Pre-baseline training. Before the onset of the study 8 probes were conducted with each participant, to determine the mean duration of performance of the RMIA sequence (six large and small motor actions, presented by the instructor, that each participant had to imitate within 2 sec.). The mean duration of the performance of the RMIA was $7.5 \mathrm{sec}$. for Participant A and 8.7 for Participant B. These data allowed the instructor to define the fixed time delivery of generalized social interaction by doubling the mean duration of performance of one RMIA sequence (15 seconds and 18 seconds respectively). Doubling of the mean performance time was used to prevent adventitious reinforcement of incorrect responses, as well as to control for interference of the fixed time response independent schedule with the performance of the RMIA and the echoic response (Goh, Iwata, Deleon, 2000). Three probe sessions were also conducted to test whether the Participants had the target echoic responses ("cup" and "book" for Participant A, and "paper" for Participant B in their repertoire.

Contingent Reinforcement Delivery Condition. During the contingent reinforcement delivery condition generalized social reinforcement (hugs, smiles, kisses, pats on the shoulder, tickles, verbal praise, etc.) was delivered, contingent on correct motor and echoic tact responses. More specifically, the instructor obtained the Participant's attention, by calling his/her name, and rapidly presented three large and three small motor imitation actions, with the antecedent "do this", allowing the Participants 2 sec. to respond to each of the actions. No social reinforcement was delivered during motor imitation responding. A vocal model was presented together with the respective non-vocal stimulus (e.g. a plastic cup for the vocal model "cup"), immediately after the correct performance of the RMIA. If the Participant responded correctly to both the RMIA and the echoic tact, the instructor delivered generalized social reinforcement for $3 \mathrm{sec}$. If incorrect RMIA and/or echoic responses occurred, the instructor turned her head and ignored the Participant for $5 \mathrm{sec}$., before the presentation of the next instructional opportunity.

FT Delivery of Social Interaction without Extinction. During this condition, social interaction was delivered on a fixed time (FT) 15 seconds interval schedule for Participant A and on a fixed time (FT) 18 seconds interval schedule for Participant B, when incorrect RMIA and/or echoic responses occurred (Car, et al., 1998; Goh, et al., 2000; Guerin, 1994; Fisher, et al., 1997; Kahng, et al., 2000; Lalli, et al., 1997; Poling \& Normand, 1999; Thompson \& Iwata, 2005; Vollmer \& Hackenberg, 2001). The researcher used a stopwatch that started at the same time with the presentation of the RMIA. If an incorrect response (motor or echoic) occurred, the researcher waited until $15 \mathrm{sec}$ (Participant A) or $18 \mathrm{sec}$. (Participant B) had elapsed, and then delivered generalized social interaction. 
In the case of correct echoic responses, however, contingent generalized social reinforcement was delivered in order to control for possible extinction of correct echoic responses (Car, et al., 1998; Fisher, et al, 1997; Lalli, et al., 1997).

The instructor conducted the experiment in 20 trial sessions. The total number of sessions across all four experimental conditions, within each experimental design, was kept constant (8 sessions per condition for both experimental designs implemented on Participant A, and 5 sessions per condition, for the experimental design implemented on Participant B). Keeping the number of 20-trial sessions constant across experimental conditions was necessary in order to control for the number of instructional opportunities as a possible confounding variable for the number of correct echoic responses.

The duration of each delivery of generalized social interaction across both experimental conditions was held constant ( 3 seconds), so that it would provide a way to measure the total amount of generalized social interaction delivered. Table 1 summarizes the total amount (duration) of generalized social reinforcement delivered across the two experimental conditions for Participant A and Participant B. In order to establish an initial deprivation state, there was no social interaction between the Participants and the instructor before the onset of each session, throughout the experiment.

Table 1. Total amount of generalized social reinforcement (in sec) delivered during the two experimental conditions for Participant A and Participant B.

\begin{tabular}{ccc}
\hline & Participant A & \\
& Fixed Time Delivery & Contingent Delivery \\
"Cup" & $960 \mathrm{sec}$ & $465 \mathrm{sec}$ \\
"Book" & $960 \mathrm{sec}$ & $552 \mathrm{sec}$ \\
& Participant B & \\
& Fixed Time Delivery & Contingent Delivery \\
& 600 & 435 sec
\end{tabular}

\section{Results}

Figure 1 shows the number of correct RMIA responses and correct echoic tacts ("cup") that Participant A emitted across the two different reinforcement contingencies conditions in the first reversal experimental design. Initially, three probe sessions (20 trials each) were conducted, in order to determine whether Participant A could emit the echoic tact "cup", without the performance of the RMIA. Figure 1 shows that Participant A emitted 0 echoic tacts when the instructor presented the actual cup together with the vocal model "cup". In the FT delivery without extinction condition, the instructor conducted 8 sessions (20 trials each), during which the participant emitted a mean of 19 
correct RMIA responses and a mean of 2 correct echoic responses. Data were overall stable with a zero trend.

During the first contingent delivery condition, data on the number of correct RMIA responses emitted were overall stable with a zero trend and a mean of 19.7. Data on the correct echoic tacts emitted were variable, but with an overall ascending trend and a mean of 8.25. When returning to the FT delivery condition, data on the RMIA performance showed a zero trend. The mean number of correct responses was 19. Data on the number of correct echoic tacts were stable, with a zero trend and a mean of 3.75. During the last contingent delivery condition, data on the correct RMIA responses were overall stable, with a zero trend and a mean of 19. Data collected on the number of correct echoic tacts were overall stable, with a zero trend and a mean of 11.

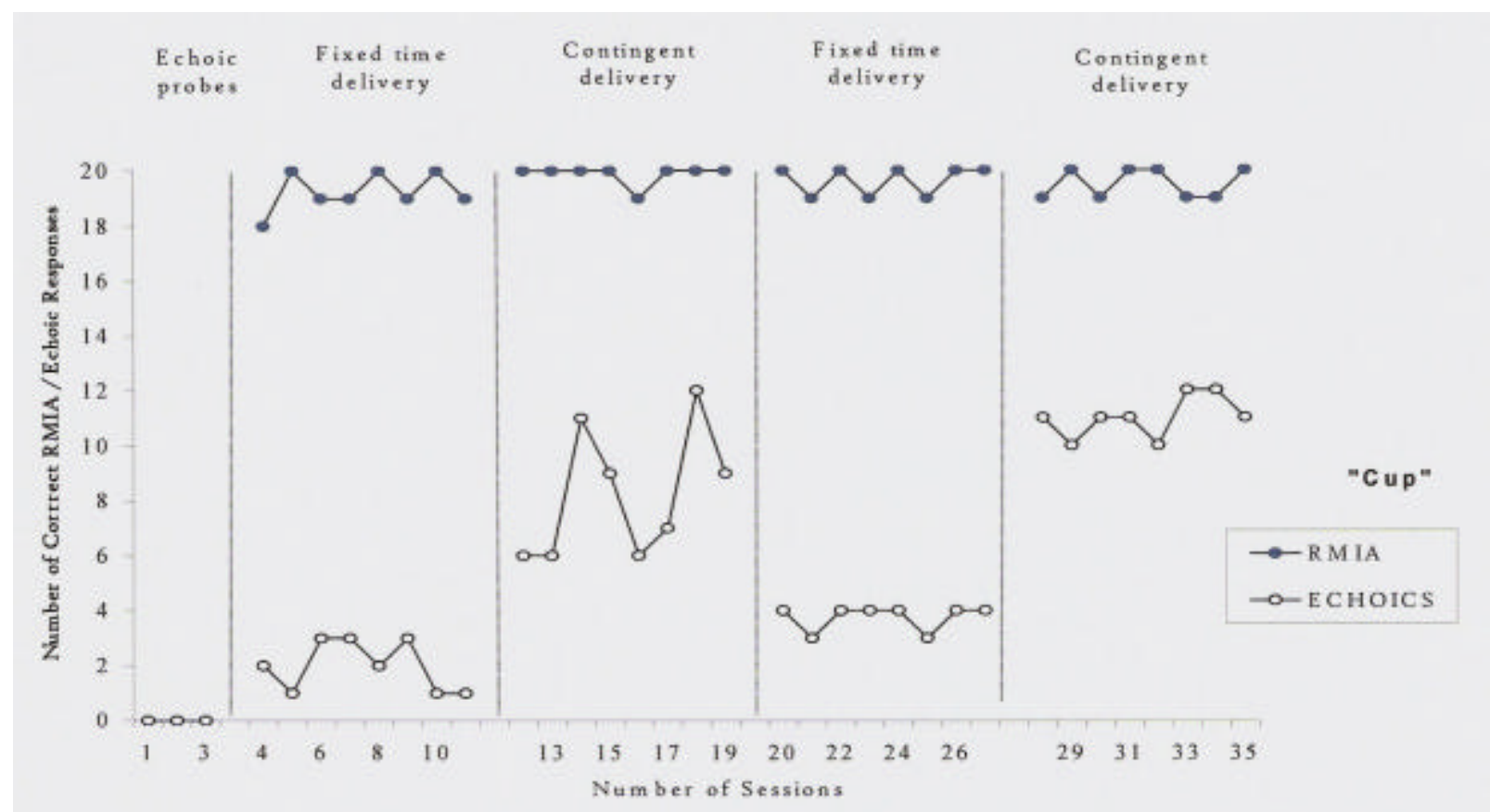

Figure 1. Number of Correct RMIA responses and correct echoic tacts emitted by participant A during fixed time delivery (satiation), and Contingent delivery (deprivation) conditions for the form "cup".

Figure 2 shows the second reversal experimental design implemented on Participant A, during which, FT delivery without extinction and contingent delivery conditions were introduced in reversed order, to control for possible sequence effects. Data were collected on the echoic tact "book". Probe sessions data showed that Participant A did not have the echoic tact "book" in his repertoire. In the first experimental condition (contingent delivery), correct RMIA responses data were variable, with a zero trend and a mean of 19.1 Data on correct echoic tacts were variable, with a steep ascending trend and a mean of 8. During the first FT delivery condition, data on the number of correct RMIA were stable, with a zero trend and a mean of 19.5. Correct echoic tacts data were variable, with an overall descending trend and a mean of 6.4. During the second contingent delivery condition, data on the RMIA correct responses were stable, with a zero trend and a mean of 19.8. Data on the number of correct echoic tacts were variable, with an overall ascending trend and a mean of 15.1.During the last FT delivery condition, data on correct RMIA responses were overall stable, with a zero trend and a 
mean of 19.4. Data on correct echoic responses were variable, with an overall descending trend and a mean of 4.3 .

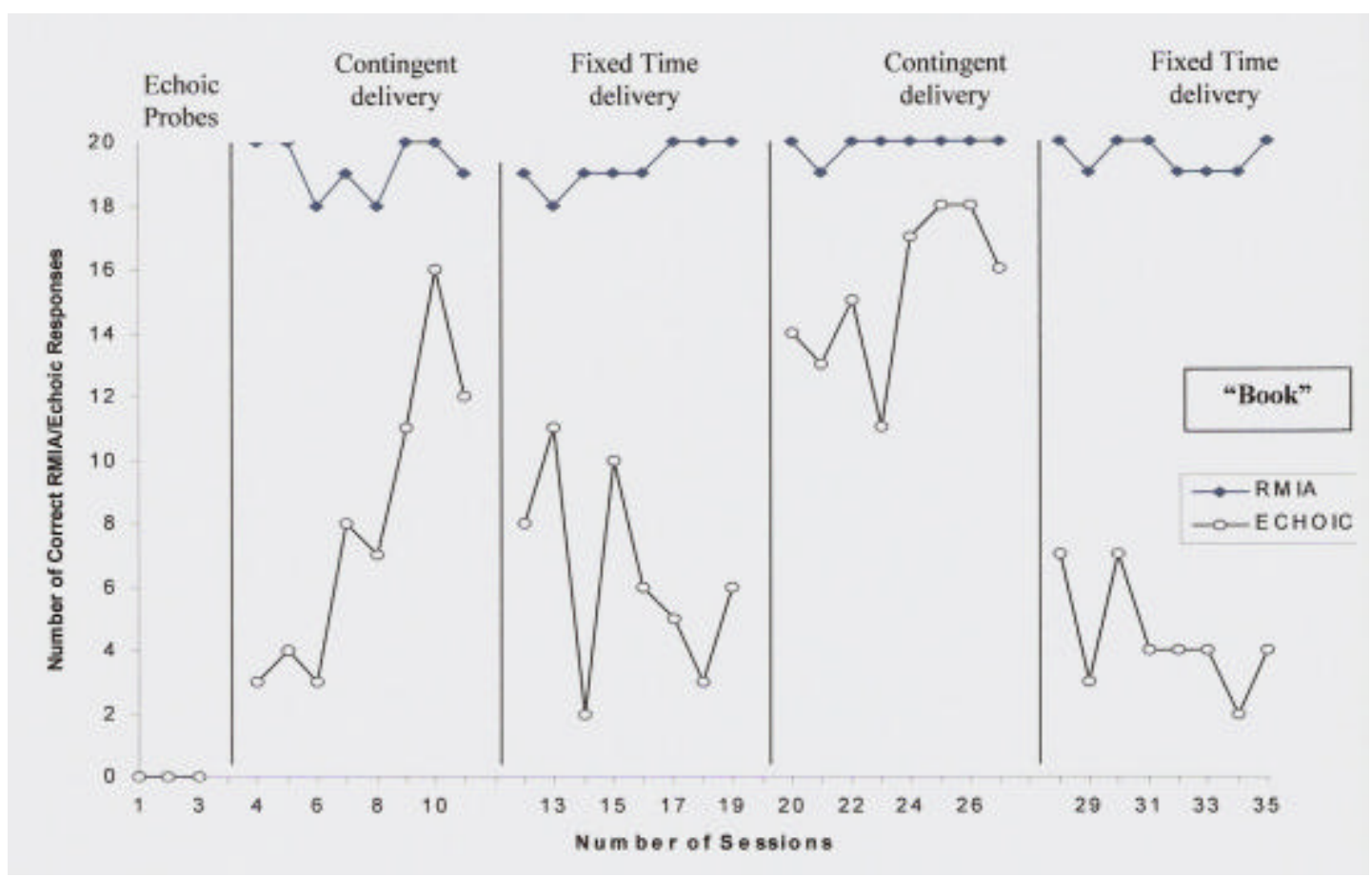

Figure 2. Number of Correct RMIA responses and correct echoic tacts emitted by participant A during fixed time delivery (satiation), and Contingent delivery (deprivation) conditions for the form "book".

Figure 3 shows the reversal experimental design implemented on Participant $\mathrm{B}$, in order to replicate the last reversal design implemented on Participant A. The echoic tact for this design was the vocal form "paper". Three probe sessions showed that Participant B did not have this echoic form in her repertoire (3 sessions at 0 ). During the first contingent delivery condition, data on correct RMIA responses had an overall ascending trend and a mean of 19. Data on the number of correct echoic responses had a steep ascending trend and a mean of 11.2. During the first FT delivery condition, data on the number of correct RMIA responses were variable, with a mean of 18, while data on correct echoic tact response were variable, with an overall descending trend and a mean of 7 . During the second contingent delivery condition, data on the RMIA were stable, with a zero trend and a mean of 19.6, while data on correct echoic tacts were variable, with a zero trend and a mean of 17.8. During the last FT delivery condition, data on correct RMIA responses were variable, with a zero trend and a mean of 18.6. Data on correct echoic tacts were stable with a descending trend and a mean of 12. 


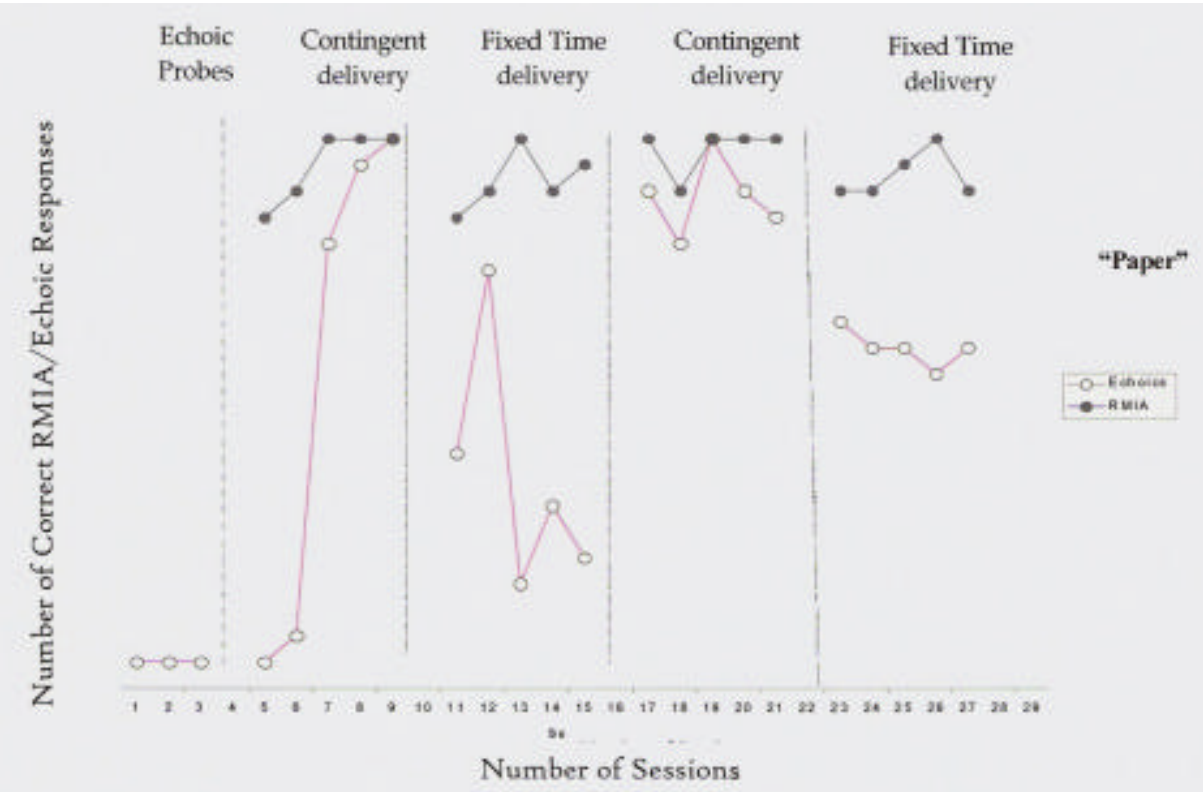

Figure 3. Number of Correct RMIA responses and correct echoic tacts emitted by participant B during fixed time delivery (satiation), and Contingent delivery (deprivation) conditions for the form "paper."

Table 2. Total number of opportunities, total number of correct echoic tacts, mean number and range of correct echoic tact responses for the forms "cup", "book" for participant A, and "paper" for participant B.

\begin{tabular}{|c|c|c|}
\hline \multicolumn{3}{|c|}{ Participani $A$} \\
\hline "Cup" & Fixed Time Delivery & Contingent Delivery \\
\hline Total Number of Sersions & 16 & 16 \\
\hline Toral Number of Opportuniti & 320 & 320 \\
\hline Toral Carrect Respanses & 44 & 155 \\
\hline Mean & 2.8 & 9.7 \\
\hline Range & $(1.4)$ & $(6-12)$ \\
\hline "Book" & Fixxed Tüme Delivery & Contingent Defivery \\
\hline Total Number of Sessions & 16 & 16 \\
\hline Total Number of Opportimiti & 320 & 320 \\
\hline Total Cornecr Responses & 88 & 184 \\
\hline Mean & 5.35 & 11.55 \\
\hline \multirow[t]{2}{*}{ Range } & $(2-11)$ & $(3-18)$ \\
\hline & Participant B & \\
\hline "Paper" & Fixed Time Delivery & Contingent Delivery \\
\hline Total Number of Sessians & so & 10 \\
\hline Total Number of Opportuniti & 200 & 2000 \\
\hline Total Correct Responses & 96 & 145 \\
\hline Mean & 9.6 & 18.5 \\
\hline Ramge & $(3-15)$ & $(0-20)$ \\
\hline
\end{tabular}


Table 2 summarizes the number of echoic tact opportunities, the number of correct echoic tact responses, the mean number, and the range of correct echoic tacts, across the two experimental conditions of FT delivery and contingent delivery for the forms "cup" and "book" for participant A and "paper" for Participant B.

\section{Discussion}

The purpose of the study reported here was to investigate the role of different contingencies of social reinforcement in the acquisition of first instances of echoic tacts (echoics taught under the controlling variables of tacts) (Tsiouri \& Greer, 2003). Thus, social interaction (praise, attention, physical interaction), which is considered the natural consequence for the echoic and the tact (Skinner, 1957; Stafford, Sundberg, Braam, 1988), was delivered on different reinforcement contingencies, during two experimental conditions: a) Fixed Time delivery of generalized social interaction without extinction (related to possible satiation effects) (Car, et al., 1998; Fisher, et al., 1997; Goh, et al., 2000; Kahng, et al., 2000; Lalli, et al., 1997; Poling and Normand, 1999; Vollmer, 1999), and b) contingent only upon correct motor imitation and echoic tact responses delivery of generalized social reinforcement. We posed two experimental questions: 1) Would different contingencies of delivery of social reinforcement, control the effectiveness of the rapid motor imitation sequence in inducing echoic tacts? 2) Would these different social reinforcement contingencies affect RMIA responses?

Data showed that across all three reversal experimental designs, counterbalanced across satiation and deprivation condition, there was a functional relationship between the number of correct echoics and contingent only upon correct responses delivery of social reinforcement. The level of correct echoic tacts was significantly higher during this experimental condition, while data dropped to a low level during the FT delivery of social interaction without extinction condition.

Across all three reversal experimental designs, there was no effect of the FT delivery without extinction condition or the contingent reinforcement delivery condition on the correct performance of the RMIA. Data remained at a high level across both conditions, which showed that generalized social reinforcement was not functioning as a controlling variable for the performance of the RMIA.

This finding is consistent with similar experimental results derived from Peterson and Whitehurst (1971) and Steinman and Boyce (1971), who implemented a DRO procedure in order to test whether imitative behavior was maintained by contingent reinforcement operations. They found that imitative responding remained at high levels and was not affected by the noncontingent delivery of reinforcement. Whitehurst, 1971; Whitehurst, 1977 suggested that setting events such as the child's history of compliance or non-compliance with adult's instructions, the presence or the absence of the adult in the room (Peterson and Whitehurst, 1971) and the presence or absence of explicit instructions, as to which stimuli the child should respond to (Steinman, 1970), could be the controlling variables in effect for the performance of generalized motor imitation (responding to previously reinforced and not reinforced imitations).

In our study, the high levels of correct RMIA responding, regardless of the reinforcement contingencies in effect, were probably a function of similar controlling variables or setting events. Participants were under good instructional control, and had a previous history of educational reinforcement (Skinner, 1957), when performing large and small motor imitation actions with the 
instructor (who was their classroom teacher). Participants demonstrated a generalized motor imitation repertoire before the onset of the study and had received explicit training to increase the rate of their RMIA performance during pre-baseline training. Therefore, one can assume that the performance of random large and small motor actions, that the instructor modeled, was reinforcing per se, regardless of the social reinforcement contingencies in effect during each experimental condition.

Echoic tact responses, on the other hand, were a function of the amount of generalized social interaction, delivered under two different contingencies. Contingent delivery of social reinforcement increased correct echoic tact responding, when the RMIA procedure was implemented to induce first instances of correct echoic tact responses (Ross and Greer, 2003; Tsiouri and Greer, 2003). When the amount of social interaction increased, (during the FT delivery without extinction condition), the level of correct echoic tact responses dropped, despite the fact that contingent social reinforcement of correct echoics was still in effect.

How can we explain the differences, however, between RMIA responding and echoic tact responding, under different contingencies of reinforcement. We can better answer this question by posing another type of question: are motor imitation responses and echoics two different response classes?

Earlier and current literature on generalized imitation, provided evidence towards viewing imitation in general as one functional response class, with no distinct topographical boundaries. Sherman (1965) extended the class of motor imitation to include vocal imitation by shaping responses that were closer approximations to vocalizations such as oral motor imitation. Peterson (1968) was successful in inducing non-imitative responses (one-step directions) without prior training, when they were interspersed among reinforced imitative responses. Poulson and Kymissis (1988); Poulson and Kymissis (1996); Steinman (1970); Steinman and Boyce (1971); suggested that both motor and vocal generalized imitation follow the same operant acquisition paradigm, which involves not only contingent social reinforcement but also the learning of the rule "do as the model says". Thus, complying with the model is the controlling variable for the emergence of the generalized imitation response class

Another body of research on generalized imitation, however, suggests that there are distinct topographical boundaries between generalized imitation classes and that the boundaries are related to the previous training histories (Garcia, Baer and Firestone, 1971; Young; Krantz, McClannahan \& Poulson, 1994; Whitehurst, 1971). According to the results of these studies, data showed that generalized imitation (from reinforced to non-reinforced responses) occurred more often within the same response class (e.g. from large motor imitation actions to small motor imitation actions), than across different response classes (e.g., from motor imitation to vocal imitation).

Skinner (1957) suggested that imitation is not inherent, but is acquired quickly at the early stages of life and evidence has accrued that this is the case for observational learning at later stages (Greer, Singer-Dudeck, \& Gautreaux, 2006). Reinforcing contingencies evoke imitative responses, and not the behavior of the model. At most, what one can argue is that behaving similar to a model becomes a reinforcer for the observer, because of a previous history of observation of the outcomes or the effects of this particular behavior. Even if we accept, however, that generalized imitation comprises one response class that follows the operant behavior paradigm, this does not suggest that we deny the existence of distinct contingencies that are characteristic of only echoic behavior. Echoics form their 
own separate, functionally independent operant class. This response class is under the control of specific variables, such as generalized social reinforcement and a vocal stimulus that involves a combination of muscular movement and a specific sound pattern (Skinner, 1957).

This study provides evidence towards the functional independence of echoic tacts and generalized motor imitation responding. Echoics under the controlling variables of tacts were sensitive to contingent reinforcement delivery conditions, while RMIA responding seemed to be under the controlling variables of the "do as the model says" paradigm, and at the same time insensitive to the reinforcement contingencies under the different experimental conditions.

More recently, the research on the formation of higher order operants, as a function of rapidly alternating exemplar experiences, suggest that the procedure of inducing echoic to tacts or echoics to mands following imitative responses may act to join the two initially independent response classes of see and do to hear and say as a new duplic higher order operant. That is just as the rapid alternation of listener and speaker responses to a single stimulus has acted to induce the higher order operants involved in Naming (Fiorile \& Greer, 2007; Greer, Stolfi, Chavez-Brown, \&Rivera-Valdes, 2005) and the higher order operants involved in joining saying and writing (Greer, Yuan, \& Gautreaux, 2005) it is possible that rapidly alternating see do with hear say opportunities results in the joining of the imitative class with the echoic class resulting in a higher order duplic operant (Greer \& Ross, 2008).

We also have to point out the possible importance of the FT delivery of social interaction without extinction procedure, on the acquisition of first instances of echoic tact behavior. There is a possible satiation effect that this procedure creates, when compared to the contingent reinforcement delivery condition (Car, et al., 1998; Fisher, et al., 1997; Goh, et al., 2000; Kahng, et al., 2000; Lalli, et al., 1997). The amount of generalized social interaction during the FT condition was significantly higher than during the contingent delivery condition (Table 1). Further experimental manipulation of the total amount of generalized social reinforcement though is needed, in order to investigate the possible motivational variables in effect, when teaching echoic tact responses. Establishing operations, such as satiation vs. deprivation from generalized social reinforcement (attention, social praise and other forms of educational reinforcement), should be thoroughly utilized, not only when teaching the mand function but also when teaching echoic and independent tacts. This line of research can contribute to the development of motivational instructional procedures that would achieve rapid increase in the echoic and independent tacting repertoire of children with severe language delays in the Autistic Spectrum Disorders.

\section{References}

Bijou, W.S., Baer, D.M. (1967). Child development: Readings in experimental analysis. AppletonCentury-Crofts, New York.

Baer, D.M., Peterson, R.F., \& Sherman, J.A. (1967). The development of imitation by reinforcing behavior similarity to a model. Journal of the Experimental Analysis of Behavior, 10, 405-416

Caroll, R. J., \& Hesse, B. E. (1987). The effects of alternating mand and tact acquisition training on the acquisition of tacts. The Analysis of Verbal Behavior, 5, 55-65.

Carr, J.E., Bailey, J.S., Ecott, C.L., Lucker, K.D., Weil, T.M. (1998). On the effects of noncontingent delivery of differing magnitudes of reinforcement. Journal of Applied Behavior Analysis, 31, 313-321. 
Cooper, J.O., Heron, T.E., \& Heward, W.L. (1987). Applied Behavior Analysis. New York: Macmillan.

Fisher, S.M., Iwata, B.A., Mazzaleski, J.L. (1997). Noncontingent delivery of arbitrary reinforcers as treatments for self-injurious behavior. Journal of Applied Behavior Analysis, 30, 239-249.

Fiorile, C. A. \& Greer, R. D. (2007). The induction of naming in children with no echoic-to-tact responses as a function of multiple exemplar instruction. The Analysis of Verbal Behavior, 23, 71-88.

Gaines, R., Leaper, C., Monahan, C., \& Weickgenant, A.(1988). Language learning and retention in young language disordered children. Journal of Autism and Developmental Disorders, 18, 281296.

Garcia, E., Baer, D. M., \& Firestone, I. (1971). The development of generalized imitation within topographically determined boundaries. Journal of Applied Behavior Analysis, 4, 101-112.

Goh, H., Iwata, B.A., Deleon, I.G. (2000). Comparison between noncontingent and contingent reinforcement schedules during response acquisition. Journal of Applied Behavior Analysis, 33, 195-207.

Greer, R.D., McCorkle, N., \& Williams, G. (1989). A sustained analysis of the behaviors of schooling. Behavioral Residential Treatment, 4, 113-141.

Greer, R.D., \& McCorkle, N., (1996). Preschool Inventory of Repertoires for Kindergarten. Fred S. Keller School and CABAS ${ }^{\circ}$ : Yonkers, NY.

Greer, R.D. (2001). Teaching operations for verbal behavior. Yonkers, NY:CABAS and the Fred S. Keller School.

Greer, R. D., \& Keohane, D. (2004). A real science of technology of teaching. In D.J. Moran \& R.W. Malott, (Eds.). Evidence based educational methods (pp. 23-46). New York: Elsevier/Academic Press.

Greer, R.D., Keohane, D., Healy, O. (2002). Quality and comprehensive application of behavior analysis to schooling. The Behavior Analyst Today, 3, (2), 120-132.http://www.behavioranalyst-online.org.

Greer, R. D. \& Keohane, D. D. (2005). The evolution of verbal behavior in young children. Behavioral Development Bulletin, 1, 31-48. Reprinted in 2006 in the Speech-Language Pathology and Applied Behavior Analysis, 1 (2), 111-141. Available at www.behavioranalyst-today.com.

Greer, R.D., \& Ross, D. E. (2008). Verbal Behavior Analysis: Developing and expanding verbal capabilities in children with language delays. Boston: Allyn \& Bacon/Merrill. [ISBN-13: 0-20545837-0 and ISBN-10: 0-205-45837-8]. 
Greer, R.D., Singer-Dudek, J., \& Gautreaux, G. (2006). Observational learning. International Journal of Psychology, 41(6), 486-489.

Greer, R. D., Stolfi, L., Chavez-Brown, M., \& Rivera-Valdez, C. (2005). The emergence of the listener to speaker component of naming in children as a function of multiple exemplar instruction. The Analysis of Verbal Behavior, 21, 123-134.

Greer, R. D., Yuan, L. \& Gautreaux, G. (2005). Novel dictation and intraverbal responses as a function of a multiple exemplar history. The Analysis of Verbal Behavior, 21, 99-116. reprinted in 2006 in the Speech-Language Pathology and Applied Behavior Analysis, 1 (2), 111-141. Available at www.behavior-analyst-today.com

Guerin, B. (1994). Analyzing social behavior: Behavior analysis and the social sciences. Reno, NV: Context Press.

Hagopian, L.P., Crocket, J., Van Stone, M., Deleon, E.G., Bowman, L.G. (2000). Effects of noncontigent reinforcement on problem behavior and stimulus engagement: the role of fixed time delivery, extinction, and alternative reinforcement. Journal of Applied Behavior Analysis, $33,433-451$.

Hall, G., \& Sundberg, M.L. (1987). Teaching mands by manipulating conditioned establishing operations. The Analysis of Verbal Behavior, 5, 41-53.

Hart, B., \& Risley, T.R. (1968). Establishing use of descriptive adjectives in the spontaneous speech of disadvantaged preschool children. Journal of Applied Behavior Analysis, 1, 109-120.

Hart, B., \& Risley, T.R. (1974). Using preschool materials to modify the language of disadvantaged children. Journal of Applied Behavior Analysis, 7, 243-256.

Hart, B., \& Risely, T.R. (1995). Meaningful differences in the everyday life of America's children. Baltimore, M.D: Paul Brookes.

Hart, B., \& Risely, T.R. (1999). The social world of children learning to talk. Baltimore, MD: Paul Brooks.

Kahng, S., Iwata, B.A., Deleon, I.G., and Wallace, M.D. (2000). A comparison of procedures for programming noncontingent reinforcement schedules. Journal of Applied Behavior Analysis, $33,223-233$.

Lalli, J.S., Casey, S.D., \& Kates, K. (1997). Noncontingent reinforcement as treatment for severe problem behavior: some procedural variations. Journal of Applied Behavior Analysis, 30, 127137.

Lovaas, O.I. (1977). The autistic child: Language development through behavior modification. New York: Irvington Press.

Marcus, B.A., Vollmer, T.R. (2000). Combining noncontingent reinforcement and differential 
reinforcement schedules as treatment for aberrant behavior. Journal of Applied Behavior Analysis, 29, 43-51.

Michael, J. (1982). Distinguishing between discriminative and motivational functions of stimuli.

Michael, J. (1983). Evocative and repertoire altering effects of an environmental event. The Analysis of Verbal Behavior, 4,19-21.

Michael, J. (1988).The establishing operation and the mand. The Analysis of Verbal Behavior, 6, 3-9.

Michael, J. (2000). Implications and refinements of the establishing operation concept. Journal of Applied Behavior Analysis, 33, 401-411.

Partington, J., \& Sundberg, M.L. (1998). Teaching language to children with autism and other developmental disabilities. Danville, CA: Behavior Analyst, Inc.

Peterson, R.F. (1968). Imitation: A basic behavioral mechanism. In H.N. Sloane, Jr. and B.MacAulay (Eds). Operant procedures in remedial speech and language training (pp.53-77). Reno, NV; Context Press.

Peterson, R.F., \& Whitehurst, G.J. (1971). A variable influencing the performance of generalized imitation behaviors. Journal of Applied Behavior Analysis, 4, 1-9.

Piazza, C.C., Fischer, W.W., Hagopian, L.P., Bowman, L.G., Lisa, T. (1996). Using a choice assessment to predict reinforcer effectiveness. Journal of Applied Behavior Analysis, 29, 1-11.

Pistoljevic, N. and Greer, R. D. (2006). The Effects of Daily Intensive Tact Instruction on Preschool Students' Emission of Pure Tacts and Mands in Non-Instructional Setting. Journal of Early and Intensive Behavioral Interventions, 103-120. Retrieved May 1, 2006 from online at http://www.behavior-analyst-online.org

Poling, A., \& Normand, M. (1999). Noncontingent reinforcement; an inappropriate description of time- based schedules that reduce behavior. Journal of Applied Behavior Analysis, 32, 237-238.

Poulson, C.l. (1983). Differential reinforcement of other- than-vocalization as a control procedure in the conditioning of infant vocalization rate. Journal of Experimental Child Psychology, 36, 471-489.

Poulson, C.L., \& Kymissis, E. (1988). Generalized imitation in infants. Journal of Experimental Child Psychology, 51, 267-279.

Poulson, C.L., \& Kymissis, E.(1996) The operant language acquisition paradigm and its empirical support. In S.W. Bijou, E.Ribes.(Eds).New directions in behavior development (p.p.73-88). Reno, NV: Context Press.

Reynolds, G.S. (1961). Behavioral contrast. Journal of the Experimental Analysis of Behavior, 4, 57-71. 
Ross, D.E., \& Greer, D.R. (2003). Generalized imitation and the mand: inducing first instances of functional speech in young children with autism. Research in Developmental Disabilities, 376, $1-17$.

Schauffler, G. and Greer, R. D. (2006). The Effects of Intensive Tact Instruction on AudienceAccurate Tacts and Conversational Units and Conversational Units. Journal of Early and Intensive Behavioral Interventions, 120-132. Retrieved May 1, 2006 from online at http://www.behavior-analyst-online.org

Selinske, J., Greer, R.D., \& Lodhi, S. (1991). A functional analysis of the Comprehensive Application of Behavior Analysis to Schooling. Journal of Applied Behavior Analysis, 13, 645-654.

Sherman, J.A. (1965). Use of reinforcement and imitation to reinstate verbal behavior in inmate psychotics. Journal of Abnormal Psychology, 12, 40-65.

Skinner, B.F. (1957). Verbal Behavior. Englewood Cliffs, NJ: Prentice Hall.

Stafford, M.W., Sundberg, M. L., Braam, S.J. (1988). A preliminary investigation of the consequences that define the mand and tact. The Analysis of Verbal Behavior, 6, 61-71.

Steinman, W.M. (1970). The social control of generalized imitation. Journal of Applied Behavior Analysis, 3, 159-167.

Steinman, W.M., \& Boyce, K.D. (1971). Generalized imitation as a function of discrimination difficulty and choice. Journal of Experimental Child Psychology, 11, 251-265.

Sundberg, M.L., Milani, I., \& Partington, J. (1977). The use of sign language with hearing, non-vocal mentally impaired persons. Paper presented at the 85th Annual Meeting of the American Psychological Association, San Francisco.

Sundberg, M.L., \& Partington, J. (1998). Teaching language to children with autism and other developmental disabilities. Danville, CA: Behavior Analyst, Inc.

Thompson, R.H., \& Iwata, B.A. A review of reinforcement control procedures. Journal of Applied Behavior Analysis, 38, 257-278.

Tsiouri, I., \& Greer, R.D. (2003). Inducing vocal verbal behavior in children with severe language delays through rapid motor imitation responding. Journal of Behavioral Education, 12, 185-206.

Vollmer, T.R. (1999). Noncontingent reinforcement. Some additional comments. Journal of Applied Behavior Analysis, 32, 239-240.

Vollmer, T.R., Iwata, B.A. Zarcone, J.R., Smith, R.G., Mazaleski, J.L. (1993). The role of attention in the treatment of attention - maintained self-injurious behavior: Noncontingent reinforcement and differential reinforcement of other behavior. Journal of Applied Behavior Analysis, 24, 279-291. 
Vollmer, T.R., \& Hackenberg, T.D.(2001). Reinforcement contingencies and social reinforcement: Some reciprocal relations between basic and applied research. Journal of Applied Behavior Analysis, 24, 279-291.

Weisberg, P. (1963). Social and non-social conditioning of infant vocalization. Child Development, 34, 279-291.

Whetherby, A. M., \& Prizant, B. M. (Eds.). (2000). Autism Spectrum Disorders. A Transactional Developmental Perspective. Baltimore, Maryland: Paul H. Brookes Publishing Co.

Whitehurst, G.J. (1971). Generalized labeling on the basis of structural response classes by two young children. Journal of Experimental Child Psychology, 12, 59-71.

Whitehurst, G.J. (1977). Imitation, response novelty, and language acquisition. In B.C. Etzel, M. Leblanc, \& D.M. Baer, (Eds). New developments in behavioral research. (p.p. 119-130). Hillsdale, NJ: Laurence Erlbaum Associates, Publishers.

Williams, G. \& Greer, R.D. (1993). A comparison of verbal behavior and linguistic communication curricula for training developmentally delayed adolescents to acquire and maintain vocal speech. Behaviorology, 1, 31-46.

Yoder, P.J., \& Layton, T.L.(1988). Speech following sing language training in autistic children with minimal verbal language. Journal of Autism and Developmental Disorders, 18, 217-229.

Young, J.M., Krantz, P.J., McClannahan, L.E., \& Poulson, C.L. (1994). Generalized imitation and response-class formation in children with autism. Journal of Applied Behavior Analysis, 2, 685-697.

\section{Author Notes}

The authors express their appreciation to Gary Novak for his helpful comments

Ioanna Tsiouri, PhD., is an Adjunct Professor at the University of Thessaly, Special Education Department, Greece.

R. D. Greer is a Professor of Education and Psychology in the Department of Health and Behavior Studies at Teachers College and Graduate School of Arts and Sciences, Columbia University, New York, NY.

Correspondence should be directed to:

Ioanna Tsiouri, PhD.

Thrakis 16

Nea Ionia

Volos, 38445, Greece

e-mail: jotsiouri@yahoo.com 